\title{
Diagnosis of interspecific hybrids between Acacia mangium and A. auriculiformis using single nucleotide polymorphism (SNP) markers
}

\author{
By Vivi Yuskianti ${ }^{1), 3)}$, HuAng FA XIN ${ }^{1), 4)}$, Zhang Bian XIANG ${ }^{2), 5)}$ and Susumu Shiraishi ${ }^{2), *)}$
}

(Received $4^{\text {th }}$ November 2009)

\begin{abstract}
This paper describes a diagnostic system to verify interspecific hybrids between Acacia mangium and $A$. auriculiformis using single nucleotide polymorphism (SNP) markers. Forty-eight DNA fragments were selected based on random amplified polymorphic DNAs (RAPD) amplified across 48 individuals from each parental species, and were transformed into 44 sequence-characterized amplified region (SCAR) markers. Five SNP markers that generated species-specific alleles for each species were selected from the 28 sequenced SCARs. A multiplex single nucleotide primer extension (SNuPE) analyses of the five SNPs using 40 A. mangium, $40 \mathrm{~A}$. auriculiformis and 16 Acacia hybrids showed high discrimination power. This diagnostic system, with high discriminatory ability, provides a highly reliable and fast method for identifying interspecific hybrids of $A$. mangium and A. auriculiformis.
\end{abstract}

Key words: Acacia, interspecific hybrid, PCR, RAPD, SCAR, SNP.

\section{Introduction}

Acacia mangium Willd. is native to northern Queensland in Australia; the Western Province of Papua New Guinea; and Indonesia (Irian Jaya and Maluku), and A. auriculiformis A. Cunn. ex Benth. is native to Cape York Peninsula, Queensland and northern areas of the Northern Territory in Australia, western and southern Papua New Guinea, and Irian Jaya and the Kei Islands in Indonesia (TURNBUlL, 1986). As the two species are closely related, hybrids between them can occur spontaneously or artificially (SEDGLEY et al., 1992), and have great potential for commercial development since. Hybrids tend to exhibit improved stem straightness and roundness, and growth performance, and show intermediate wood characteristics between $A$. mangium and A. auriculiformis, and could be used for the development of disease-resistant lines (PINSO and NASI, 1991).

Tree-breeding programs for interspecific hybrids rely on an accurate identification method for parental species and certification of putative hybrids to allow

\footnotetext{
1) Graduate School of Bioresource and Bioenvironmental Science, Kyushu University, Fukuoka 812-8581, Japan.

2) Faculty of Agriculture, Kyushu University, Fukuoka 812-8581, Japan.

3) Present Address: The Center for Forest Biotechnology and Tree Improvement, Yogyakarta, Indonesia.

$\left.{ }^{4}\right)$ Present Address: Aibi Lake Wetland National Nature Reserve Administration Bureau, Bortala Prefecture, Xinjiang, China.

5) Present Address: School of Chemistry and Engineering, Shanxi University, Taiyuan 030006, China.

*) Corresponding Author: Susumu ShiRAishi. Phone and Fax: 8192642 2872. E-Mail address: sushi@agr.kyushu-u.ac.jp
}

screening of germplasm at an early stage to ensure the delivery of the desired material and obtain the predicted genetic gains (Gros-Louis et al., 2005). Many studies of hybrid identification and discrimination have been conducted; including studies of isoenzyme in pine (KoROL et al., 1995); RAPD markers in spruce (PERRON et al., 1995; NkongOlo, 1999), larch (ScheEPERS et al., 2000) and eucalyptus (DELAPORTE et al., 2001); simple sequence repeat (SSR) markers in poplar (BEKKAOUI et al., 2003; KHASA et al., 2005) and Acacia hybrid (NG et al., 2005); cytoplasmic DNA such as chloroplast DNA (cpDNA) in eucalyptus (Mc KINNON et al., 2001); cpDNA, mitochondrial DNA (mtDNA) in larch (ACHERE et al., 2004); and cpDNA and nuclear DNA (nDNA) in poplar (HOLDEREGGER et al., 2005).

A new type of marker, single nucleotide polymorphisms (SNP) (GUPTA et al., 2001; RAFALSKI, 2002; LEE et al., 2004), have attracted much attention due to their abundance in the genome and potential for use in automated high-throughput genotyping. SNPs have been used for various applications in humans (VALLONE et al., 2004; LEE et al., 2005), animals (HEATON et al., 2002; WERNER et al., 2004), and plants (BATLEY et al., 2003; VARSHNEY et al., 2007). SNP markers have a number of advantages over other markers, as they have a low mutation rate and stable inheritance. Moreover, since SNP possesses a bi-allelic nature, scoring its genotype on the basis of raw data is relatively simple.

Therefore, the main objective of this study was to develop a highly reliable and accurate diagnosis system for $A$. mangium, A. auriculiformis and their interspecific hybrids using SNP markers.

\section{Materials and Methods \\ Plant material and DNA extraction}

The samples used in this study include 48 individuals of each species from a provenance trial site at The Center for Forest Biotechnology and Tree Improvement (CFBTI) in Wonogiri, Central Java, Indonesia. Details of provenance seed origins are presented in Table 1. Sixteen Acacia hybrid samples from Quy Nhon Plantation Forest Company of Vietnam Ltd. (QPFL) were also added so that the discriminability of the new diagnosis system could be confirmed. Leaf genomic DNA was isolated using a modified CTAB method (SHIRAISHI and WATANABE, 1995) and purified with MagneSil (Promega) following the procedure described by the supplier.

\section{$R A P D$ fragment screening}

Sixty-four 13-mer RAPD primers were used for screening DNA fragments. PCR amplification was car- 
Table 1. - List of A. mangium and A. auriculiformis samples used for selecting species-specific markers.

\begin{tabular}{|c|c|c|c|c|}
\hline \multirow[b]{2}{*}{ Country } & \multicolumn{2}{|l|}{ A. mangium } & \multicolumn{2}{|c|}{ A. auriculiformis } \\
\hline & Provenance & $\begin{array}{c}\text { No. of } \\
\text { samples }\end{array}$ & Provenance & $\begin{array}{c}\text { No. of } \\
\text { samples }\end{array}$ \\
\hline \multirow{8}{*}{$\begin{array}{l}\text { Papua New } \\
\text { Guinea } \\
\text { (PNG' }\end{array}$} & Arufi Village WP & 3 & Bandaber N of Bulla WP & 2 \\
\hline & BimadebunWP & 4 & Bensbach WP & 4 \\
\hline & Boite Ne Morehead WP & 3 & Morehead R Rouku WP & 5 \\
\hline & Derideri E Morehead & 3 & & \\
\hline & Dimisisi WP & 3 & & \\
\hline & Gubam Ne Morehead WP & 3 & & \\
\hline & Kini WP & 4 & & \\
\hline & Wipim District WP & 3 & & \\
\hline \multirow{10}{*}{$\begin{array}{l}\text { Queensland } \\
\text { (QLD), } \\
\text { Australia }\end{array}$} & $135 \mathrm{~K}$ NNE Coen & 3 & Boggy Creek & 4 \\
\hline & Cassowary CK-Iron Range & 3 & F. Normamby River & 2 \\
\hline & Claudie R \& Iron RA & 4 & Kennedy River & 5 \\
\hline & Claudia River & 5 & Lower Poscoe River & 5 \\
\hline & Claudie River (Ex ACEB) & 2 & Morehead River & 4 \\
\hline & Pascoe River & 3 & Olive River & 5 \\
\hline & Pascoc RVR Area SL & 2 & (R) Orchard Melville Int & 6 \\
\hline & 35815 & & Wenlock R \& Tribs & 2 \\
\hline & & & Wenlock River & 4 \\
\hline & Tolal & 48 & Total & 48 \\
\hline
\end{tabular}

ried out in $10 \mu \mathrm{l}$ of reaction mixture containing $10 \mathrm{mM}$ Tris- $\mathrm{HCl}(\mathrm{pH} 8.3), 10 \mathrm{mM} \mathrm{KCl}, 3.0 \mathrm{mM} \mathrm{MgCl}{ }_{2}, 0.2 \mathrm{mM}$ of each dNTP, $0.025 \mathrm{U} / \mathrm{ul}$ Platinum Taq DNA polymerase (Invitrogen), $1.5 \mu \mathrm{M}$ of primer, and $10 \mathrm{ng} / \mu \mathrm{l}$ of template DNA. Amplification was performed using a thermocycler (Biometra) with an initial denaturizing process at $94^{\circ} \mathrm{C}$ for $1 \mathrm{~min}$; 45 cycles of $94^{\circ} \mathrm{C}$ for $30 \mathrm{sec}, 37^{\circ} \mathrm{C}$ for $30 \mathrm{sec}$, and $72^{\circ} \mathrm{C}$ for $90 \mathrm{sec}$; and a final cycle of $72^{\circ} \mathrm{C}$ for $7 \mathrm{~min}$. The amplified products were verified on $1.2 \%$ agarose gel, visualized by ethidium bromide staining, and photographed using a 302-nm UV transilluminator. RAPD fragments were scored in a binary data matrix as 1 (present) or 0 (absent).

\section{SCAR marker development}

Target fragments in the RAPD screening were excised from the gel using pipette-tips. A re-amplification was carried out according to the method described above except for differences in the primer concentration $(0.5 \mu \mathrm{M})$ and the amplification condition (30 cycles of $94^{\circ} \mathrm{C}$ for $30 \mathrm{sec}, 55^{\circ} \mathrm{C}$ for $30 \mathrm{sec}$, and $72^{\circ} \mathrm{C}$ for $90 \mathrm{sec}$ ). The PCR product was then ligated with a plasmid vector (pGEM-T Vector System, Promega) and transformed into E. coli (JM109 Competent Cell, TOYOBO) according to the method recommended by the supplier. A colony PCR (HATTORI et al., 1997) was amplified with the same components described above using two primers (pGE_U: 5'-TCCGGCTCGTATGTTGTGTGGA-3' and pGE_L: 5'-GTGCTGCAAGGCGATTAAGTTGG-3') for 29 cycles of $96^{\circ} \mathrm{C}$ for $15 \mathrm{sec}$ and $70^{\circ} \mathrm{C}$ for 2 min followed by one cycle of $70^{\circ} \mathrm{C}$ for $10 \mathrm{~min}$ in Gene Amp 9600 (Perkin Elmer)

From $10 \mu \mathrm{l}$ of the PCR product, $5 \mu \mathrm{l}$ were electrophoresed in $1.2 \%$ agarose gel to confirm fragment presence. If the amplification was successful, the other $5 \mu \mathrm{l}$ of the PCR product were then enzymatically treated with $1 \mathrm{U}$ each of Shrimp Alkaline Phosphatase (SAP) and Exonuclease I (ExoI) to degrade the excess of primers and dNTPs. The reaction solution was mixed thoroughly and incubated at $37^{\circ} \mathrm{C}$ for 1 hour, followed by 15 minutes at $75^{\circ} \mathrm{C}$ to inactivate the enzymes. The sequencing reaction was performed using Big Dye Terminator v1.1/v.3.1 and -21 M13/M13 REV primer (Applied Biosystems). The reactions were purified using the CleanSEQ Sequencing Reaction Clean-up system (Agencourt) according to the supplier-recommended procedure. Sequence analysis was conducted using the ABI 3100 Genetic Analyzer (Applied Biosystems). For each successfully sequenced RAPD fragment, a pair of SCAR primers (Table 2) were designed based on the fragment's nucleotide sequence. SCAR amplification was conducted according to the re-amplification procedure above except for differences in the primer concentration $(0.2 \mu \mathrm{M}$ of each primer) and amplification time $\left(30\right.$ cycles of $72{ }^{\circ} \mathrm{C}$ for $60 \mathrm{sec}$ in extension).

Sequencing for SCARs was carried out using four samples from each Acacia species according to the procedure mentioned above except for using SCAR primers (Table 2) as sequencing primers. The resulting sequences of each SCAR were aligned using Sequencher 4.2.2 (Gene Codes), a putative interspecies-specific SNP was selected, and an extension primer (Table 3) was designed based on the SNP flanking sequence.

\section{SNuPE analysis}

Amplification of multiplex SCAR was performed using the optimized primer concentration. The concentration for each SCAR primer is shown in Table 2. The condi- 
Table 2. - RAPD and SCAR primer sequences and SCAR primer concentrations used in a multiplex SNuPE analysis.

\begin{tabular}{|c|c|c|c|c|}
\hline \multirow[b]{2}{*}{ Marker } & \multicolumn{2}{|l|}{ RAPD } & \multicolumn{2}{|l|}{ SCAR } \\
\hline & $\begin{array}{l}\text { Primer sequence } \\
\qquad\left(5^{\prime} \text { to } 3^{\prime}\right)\end{array}$ & $\begin{array}{l}\text { Fragment } \\
\text { length } \\
\text { (bp) }\end{array}$ & $\begin{array}{l}\text { Primer sequence } \\
\qquad\left(5^{\prime} \text { to } 3^{\prime}\right)\end{array}$ & $\begin{array}{l}\text { Primer conc. } \\
\qquad(\mu \mathrm{M})\end{array}$ \\
\hline \multirow[t]{2}{*}{ AHsnp 1} & AACGGTGACCGTA & 700 & F: ACGGTGACCGTACTCCTTCGC & 0.06 \\
\hline & & & R: GTGACCGTAGCCGCCGAATAC & 0.06 \\
\hline \multirow[t]{2}{*}{ AHsnp2 } & AGTCGGGTGGCGT & 700 & F: GTCGGGTGGCGTGGAAGGGT & 0.20 \\
\hline & & & R: GTCGGGTGGCGTTCCTCGAG & 0.20 \\
\hline \multirow[t]{2}{*}{ AHsnp3 } & GGAGGAGAGGCGT & 550 & F: GGAGGAGAGGCGTGCCGGGG & 0.12 \\
\hline & & & R: GGAGGAGAGGCGTCCAACCA & 0.12 \\
\hline \multirow[t]{2}{*}{ AHsnp4 } & GGAGGAGAGGAGC & 350 & F: GGAGGAGAGGAGCCAGTTGAG & 0.12 \\
\hline & & & R: GGAGGAGAGGAGCACTCACACA & 0.12 \\
\hline \multirow[t]{2}{*}{ AHsnp5 } & GGAGGAGAGGAGC & 250 & F: GGAGGAGAGGAGCGTAGCCC & 0.20 \\
\hline & & & R: GGAGGAGAGGAGCCCATTAGG & 0.20 \\
\hline
\end{tabular}

Table 3. - Extension primer sequences and concentrations for a multiplex SNuPE analysis, and bi-allele migrations in five markers.

\begin{tabular}{|c|c|c|c|c|c|c|c|}
\hline \multirow{2}{*}{ Marker } & \multirow{2}{*}{$\begin{array}{l}\text { Extension primer sequences } \\
\qquad\left(5^{\prime} \text { to } 3^{\prime}\right)\end{array}$} & \multirow{2}{*}{$\begin{array}{l}\text { Primer } \\
\text { length } \\
\text { (nt) }\end{array}$} & \multirow{2}{*}{$\begin{array}{c}\text { Primer } \\
\text { concentration } \\
(\mu \mathrm{M})^{\mathrm{a}}\end{array}$} & \multicolumn{2}{|c|}{ Allele $\mathbf{M}^{\mathrm{b}}$} & \multicolumn{2}{|c|}{ Allele $\mathrm{A}^{\mathrm{b}}$} \\
\hline & & & & Base & Size $^{\mathrm{c}}$ & Base & Size $^{\mathrm{c}}$ \\
\hline AHsnp1 & CATGGCTTCTGCATTAC & 17 & 1.0 & A & 33.2 & $\mathrm{C}$ & 33.3 \\
\hline AHsnp2 & $\mathrm{T}_{6}$-AGCTCGCTATATATGTT & 23 & 1.0 & $\mathrm{C}$ & 36.2 & A & 35.8 \\
\hline AHsnp3 & $\mathrm{T}_{12}$-GGTTCGAGCTTGGAATC & 29 & 0.7 & $\mathrm{G}$ & 38.5 & A & 39.4 \\
\hline AHsnp4 & $\mathrm{T}_{14}$-TAGCCTCCGACGTTGGC & 31 & 0.8 & $\mathrm{~T}$ & 42.6 & A & 40.6 \\
\hline AHsnp5 & $\mathrm{T}_{18}$-TCACTATTTCTTTCTCG & 35 & 1.0 & $\mathrm{C}$ & 44.8 & $\mathbf{T}$ & 46.3 \\
\hline
\end{tabular}

tions for multiplex SCAR using the touchdown PCR (Don et al., 1991) were as follows: $94^{\circ} \mathrm{C}$ for $30 \mathrm{sec}$ and $60^{\circ} \mathrm{C}$ for $60 \mathrm{sec}$ in the first cycle; then the annealing temperature was decreased $0.5^{\circ} \mathrm{C}$ every cycle from $60^{\circ} \mathrm{C}$ to $55^{\circ} \mathrm{C}$, at which temperature 9 cycles were carried out; 20 cycles of $94^{\circ} \mathrm{C}$ for $30 \mathrm{sec}, 55^{\circ} \mathrm{C}$ for $30 \mathrm{sec}$, and $72^{\circ} \mathrm{C}$ for $60 \mathrm{sec}$.

The electrophoretic mobility of the extension products was adjusted by varying the length of the extension primer using 5' non-homologous (poly T) tails (Table 3). Extension reactions were carried out in $10-\mu l$ reactions containing $0.5 \mu \mathrm{l}$ of ABI Prism SNaPshot Multiplex Ready Reaction Mix (Applied Biosystems), $1.8 \mu \mathrm{l}$ of $5 \mathrm{X}$ Sequencing Buffers (Applied Biosystems), $1 \mu$ of multiplex PCR products, and extension primers whose concentrations were adjusted as shown in Table 3. Extension reaction was performed in a Thermocycler (Biometra) for 25 cycles of $96^{\circ} \mathrm{C}$ for $10 \mathrm{sec}, 50^{\circ} \mathrm{C}$ for $5 \mathrm{sec}$, and $60^{\circ} \mathrm{C}$ for $30 \mathrm{sec}$. One unit of SAP was added to remove the 5' phosphoryl groups that alter the migration of the unincorporated ddNTPs and thus prohibit interference.
The reaction was incubated at $37^{\circ} \mathrm{C}$ for 1 hour followed by 15 minutes at $75^{\circ} \mathrm{C}$ to inactivate the enzymes.

Fluorescently labeled extension products were mixed with Hi-Di Formamide (Applied Biosystems) and LIZ120 internal sizing standard (Applied Biosystems), and denaturized at $95^{\circ} \mathrm{C}$ for 5 minutes for loading onto an ABI 3100 Genetic Analyzer. Data analysis was performed using GeneMapper v 3.7 Software (Applied Biosystems).

\section{Results}

\section{$S C A R$ marker development}

RAPD fragment screening across 48 samples for each of A. mangium and A. auriculiformis provided reproducible and reliable data for the selection of fragments for Acacia hybrid diagnosis. Forty-eight informative RAPD fragments were obtained (Figure 1), and SCAR markers were successfully designed for 44 out of the 48 fragments. Sequence analyses of newly designed SCARs were carried out using four samples each of $A$. mangium 


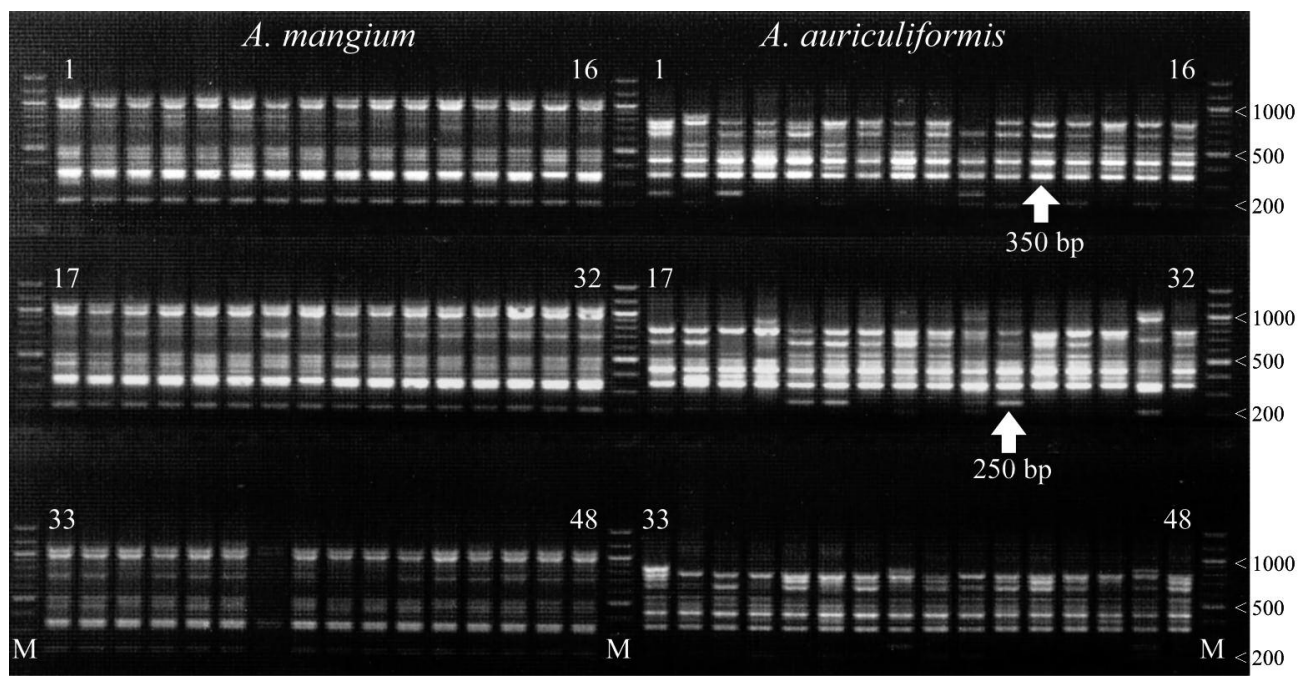

Figure 1. - Screening of RAPD fragments using 5'-GGAGGAGAGGAGC-3' primer. Two fragments at positions $250 \mathrm{bp}$ and $350 \mathrm{bp}$ were selected and developed into SCAR markers. $\mathrm{M}$ is a size marker.

and A. auriculiformis. Analysis of the SCAR markers showed that 43 SCARs were successfully amplified and only one fragment could not be amplified. Twenty-one SCARs produced monomorphic fragments in both A. mangium and A. auriculiformis, 14 SCARs had no fragment in A. mangium with monomorphic/polymorphic fragments in A. auriculiformis, and eight highlighted polymorphism in one or both Acacia species.

\section{SNP detection}

Twenty-eight SCARs, including 21 monomorphic SCARs, were further sequenced for four samples of each Acacia species. SNPs in the form of heterozygotes, point mutations and insertion/deletions (indel) at a specific base position were detected. Twenty-five out of 28 SCARs produced informative sequence data. Two SCARs did not detect any variation, while one failed to produce good sequence data. Fifteen SCARs that were considered to have useful polymorphism for hybrid diagnosis were further amplified to verify the presence of the fragment in all tested samples (48 in each Acacia species) and also to check PCR fragment quality. Five SCARs (AHsnp 1-5 in Tables 2) were finally selected and developed into extension primers (Figure 2 and Table 3 ).

\section{SNuPE analysis}

To avoid overlapping among the five markers in multiplex analyses, the extension primer length of each marker was adjusted by adding Poly-thymidine (Poly-T) tail to the 5' end following the procedure described by Applied Biosystems (Table 3). The signal intensity of the target allele for each primer in the multiplex analysis was optimized. PCR primer concentration of the marker that exhibited high signal intensity was reduced, where-

AM01 ACCATCCACGGCGTAGCCTCCGACGTTGGCTGCGTGATTCTTTTGGCACTCTCCATATCTC AM02 ACCATCCACGGCGTAGCCTCCGACGTTGGCTGCGTGATTCTTTTGGCACTCTCCATATCTC AM03 ACCATCCACGGCGTAGCCTCCGACGTTGGCTGCGTGATTCTTTTGGCACTCTCCATATCTC AM04 ACCATCCACGGCGTAGCCTCCGACGTTGGCTGCGTGATTCTTTTGGCACTCTCCATATCTC AR01 ACCATCCACGGCGTAGCCTCCGACGTTGGCAGCGTGATTCTTTTGGCACTCTCCATATCTC AR02 ACCATCCACGGCGTAGCCTCCGACGTTGGCAGCGTGATTCTTTTGGCACTCTCCATATCTC AR03 ACCATCCACGGCGTAGCCTCCGACGTTGGCAGCGTGATTCTTTTGGCACTCTCCATATCTC AR04 ACCATCCACGGCGTAGCCTCCGACGTTGGCAGCGTGATTCTTTTGGCACTCTCCATATCTC

AM01 GTGTGAGAAGTATTTTGGAGAATCCCTTCTTATCACTATTTCTTTCTCGCCTCTCTCTCTC AM02 GTGTGAGAAGTATTTTGGAGAATCCCTTCTTATCACTATTTCTTTCTCGCCTCTCTCTCTC AM03 GTGTGAGAAGTATTTTGGAGAATCCCTTCTTATCACTATTTCTTTCTCGCCTCTCTCTCTC AM0 4 GTGTGAGAAGTATTTTGGAGAATCCCTTCTTATCACTATTTCTTTCTCGCCTCTCTCTCTC AR01 GTGTGAGAAGTATTTTGGAGAATCCCTTCTTATCACTATTTCTTTCTCGTCTCTCTCTCTC AR02 GTGTGAGAAGTATTTTGGAGAATCCCTTCTTATCACTATTTCTTTCTCGTCTCTCTCTCTC AR03 GTGTGAGAAGTATTTTGGAGAATCCCTTCTTATCACTATTTCTTTCTCGTCTCTCTCTCTC AR04 GTGTGAGAAGTATTTTGGAGAATCCCTTCTTATCACTATTTCTTTCTCGTCTCTCTCTCTC Figure 2. - Partial sequence of A. mangium (AM) and A. auriculiformis (AR) genome using AHsnp4 marker (upper) and AHsnp5 marker (lower). Bold letters represent the target SNP. The underlined sequences represent extension primer sequences. 


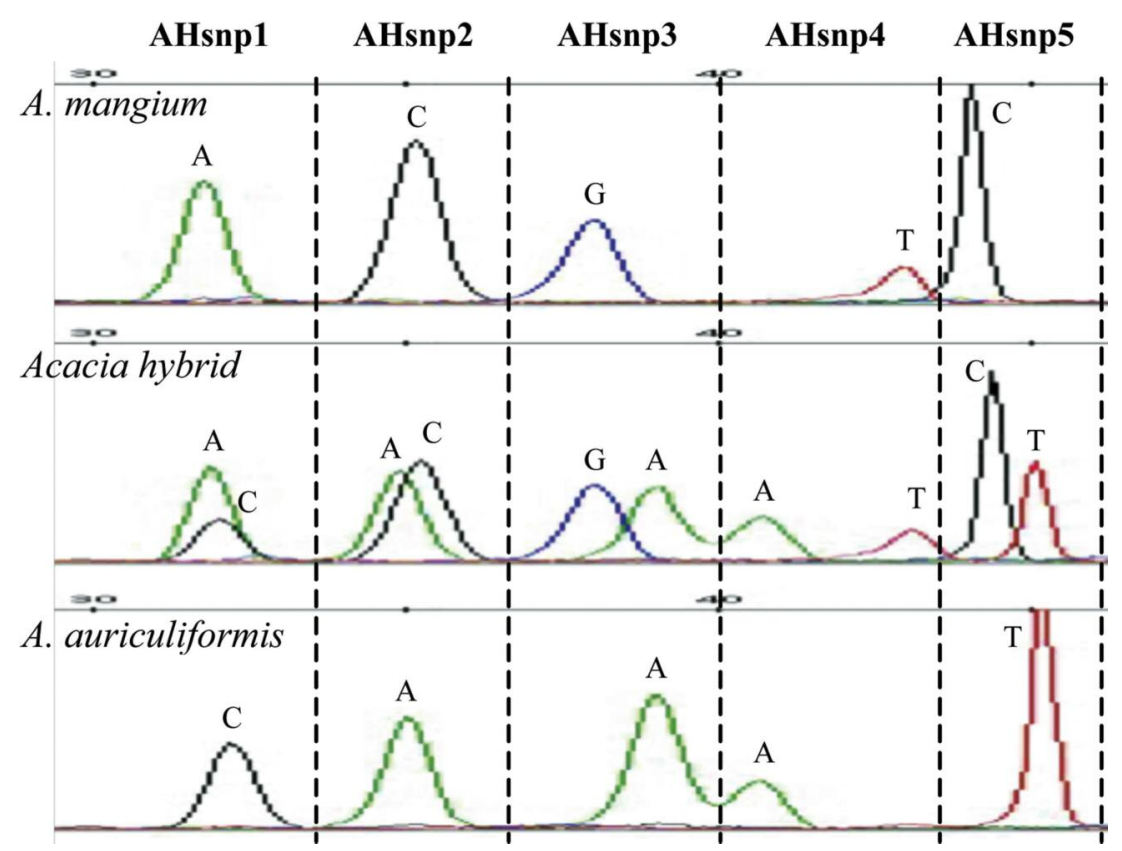

Figure 3. - Signal intensity of A. mangium, Acacia hybrid and A. auriculiformis using five markers (AHsnp1, AHsnp2, AHsnp3, AHsnp4, and AHsnp5) in a multiplex SNuPE analysis. The letter on the top of each peak refers to the SNP allele.

Table 4. - Bi-allele frequencies of five markers in an A. mangium, A. auriculiformis and Acacia hybrid.

\begin{tabular}{|c|c|c|c|c|c|c|}
\hline \multirow{2}{*}{ Marker } & \multicolumn{2}{|c|}{ A. mangium $(40)^{a}$} & \multicolumn{2}{|c|}{ A. auriculiformis $(40)^{\mathrm{a}}$} & \multicolumn{2}{|c|}{ Acacia hybrid $(16)^{\mathrm{a}}$} \\
\hline & Allele $\mathrm{M}^{\mathrm{b}}$ & Allele $A^{b}$ & Allele $\mathrm{M}^{\mathrm{b}}$ & Allele $A^{b}$ & Allele $\mathrm{M}^{\mathrm{b}}$ & Allele $A^{b}$ \\
\hline AHsnp1 & 1.00 & 0.00 & 0.00 & 1.00 & 1.00 & 1.00 \\
\hline AHsnp2 & 1.00 & 0.00 & 0.00 & 0.95 & 1.00 & 1.00 \\
\hline AHsnp3 & 1.00 & 0.08 & 0.00 & 1.00 & 1.00 & 1.00 \\
\hline AHsnp4 & 1.00 & 0.00 & 0.00 & 1.00 & 1.00 & 1.00 \\
\hline AHsnp5 & 1.00 & 0.00 & 0.00 & 1.00 & 1.00 & 0.94 \\
\hline
\end{tabular}

a Number in parenthesis represents number of sample analyzed.

${ }^{\mathrm{b}}$ Alleles $\mathrm{M}$ and $\mathrm{A}$ are species-specific alleles in A. mangium and A. auricaliformis, respectively.

as other primers were kept at a standard concentration $(0.2 \mu \mathrm{M})$. After the optimized PCR primer concentrations were obtained (Table 2), further optimization to balance the extension primer concentrations was conducted (Table 3). The process was repeated several times until a balanced signal was obtained across all markers (Figure 3).

\section{Discrimination power of the multiplex $S N u P E$ analysis}

The discrimination power of the multiplex SNuPE for the diagnosis of interspecific Acacia hybrids and their parental species was tested using 40 A. mangium, 40 A. auriculiformis and 16 Acacia hybrid samples. AHsnp1 and AHsnp4 markers were able to detect $A$. mangium-specific alleles and A. auriculiformis-specific alleles, respectively. For AHsnp3, allele A specific to A. auriculiformis was also detected in three $A$. mangium samples (8\%). For AHsnp2, allele A specific to A. auri- culiformis could not be detected in two A. auriculiformis samples. For AHsnp5, A. auriculiformis-specific allele A could not be obtained in a hybrid sample (Table 4).

\section{Discussion}

RAPD markers (WILLIAM et al., 1990) and SCAR markers (PARAN and MiCHELMORE, 1993) were employed to obtain useful fragments for hybrid diagnosis between Acacia mangium and A. auriculiformis. RAPD markers have been a commonly used method for hybrid identification; however, they are difficult to reproduce, and are sensitive to minor changes in reaction conditions (JONES et al., 1997; Mc GREGOR et al., 2000). The reliability of fragments screening was improved by developing candidate RAPD fragments into SCAR markers. SCARs have several advantages over RAPD markers, as they can target single defined loci, are less sensitive to reaction 
conditions, and scoring results is more straightforward (PARAN and Michelmore, 1993; Weng et al., 1998; BAUTISTA et al., 2002).

Identification of interspecific hybrids between A. mangium and A. auriculiformis using only two SCAR markers (HUANG et al., 2005) had been previously reported. These SCARs have been used as a means for identifying hybrids. However, in order to achieve more reliable diagnosis, more species-specific markers should be used. Fifteen polymorphic microsatellite markers have also been developed for Acacia hybrid ( $\mathrm{NG}$ et al., 2005). However, using such marker to routinely screen for hybrids might be problematic since the microsatellite markers are polymorphic in the parental species and possess intraspecific variation.

SNP-based markers offer many advantages over microsatellite markers. Namely, they are direct markers (BATLEY et al., 2003), have low mutation rates (VIGNAL et al., 2002; BATLEY et al., 2003; BRUMFIELD et al., 2003; AITKEN et al., 2004) and are more stable than other marker systems (GUPTA et al., 2001). SNPs also offer a great opportunity for unbiased sampling of loci (BRUMFIELD et al., 2003) and simple allele nomenclature (VIGNAL et al., 2002). Therefore, the SNP marker system not only offers lower cost (an estimated five to ten times lower than for microsatellites), higher repeatability and higher accuracy, but it also offers increased opportunities to develop germplasm databases that are meaningful across different organizations (JONES et al., 2007).

The high discrimination power of the new markers was confirmed using 96 Acacias and hybrids. In AHsnp1 and AHsnp4, $100 \%$ of A. mangium-specific alleles and $100 \%$ of $A$. auriculiformis-specific alleles were detected in a multiplex SNuPE analysis. However, an A. auriculiformis-specific allele in AHsnp3, was also detected at low levels in A. mangium, and A. auriculiformis-specific alleles in AHsnp2 and AHsnp5 were not detected in a few samples of $A$. auriculiformis nor in hybrid (Table 4). This suggests that the A. auriculiformis infrequently holds null alleles in addition to the species-specific alleles for these two markers.

The ability of SNP to be applied as species-specific markers found in this research is consistent with other studies. A study of soybeans for cultivar identification showed that a panel of 23 SNPs could uniquely distinguish 2,200 soybean cultivars (Yoon et al., 2007). Another study on spruce demonstrated that two SNPs (one chloroplast DNA and one nuclear DNA) can distinguish black spruce from red and white spruces at a rate of 96-100\% and that 5 SNPs (four chloroplast and on nuclear) can distinguish white spruce from red and black spruces at a rate of $100 \%$ (GERMANO and KLEIN, 1999). The infrequent presence of a specific allele in another species was also discovered in this research. The fact that the $A$. auriculiformis-specific allele (AHsnp3 allele A in Table 4) was present in A. mangium samples suggested the possibility that a common allele is shared between $A$. mangium and A. auriculiformis. However, the existence of null alleles (AHsnp2 allele A and AHsnp5 allele A in Table 4) in A. auriculiformis samples and Acacia hybrids might be the result of muta- tions, either insertion/deletion (indel) or base substitution, in the priming site of the extension primer used for $\mathrm{SNuPE}$ analysis.

The multiplexing of SNPs has been used extensively in work on humans (BRANDSTATTER et al., 2003; VALLONE et al., 2004; VALLONE and BUTLER, 2004; VALLONE et al., 2006) and plants (BATLEY et al., 2003; MoHRING et al., 2004). This paper describes a multiplex SNP analysis designed for the diagnosis of interspecific hybrids between $A$. mangium and A. auriculiformis and their parental species. The system has a high capacity to discriminate five $A$. mangium-specific alleles and five A. auriculiformis-specific alleles. Therefore, this multiplex system provides reliable, accurate and fast identification of the species-specific alleles in A. mangium and A. auriculiformis.

In conclusion, we have developed a multiplex SNuPE analysis consisting of five markers that can detect species-specific alleles in A. mangium and A. auriculiformis. The markers have high reliability for the accurate discrimination of the interspecific hybrid between A. mangium and A. auriculiformis, as well as their parental species. Various applications can be performed using this system, including; the confirmation of hybrid identity from spontaneous or artificial hybridization, the certification of commercial hybrid plantlets for afforestation, and the selection of plus hybrids from a plantation/nursery. Moreover, using this new diagnosis system, efficiency and clarification of the hybrid product can be obtained in hybrid cultivar development using a bi-species seed orchard of A. mangium and A. auriculiformis species.

\section{Acknowledgements}

We are grateful to Drs. AYPBC WIDYATMOKO and ARIF NiRSATMANTO of The Center for Forest Biotechnology and Tree Improvement, Forestry Research and Development Agency, Indonesia who provided the A. mangium and $A$. auriculiformis materials, and to Dr. KAZUYA ITO, Oji Paper Co., Ltd. for offering the hybrid materials. The author also thanks Drs. ANTo RIMBAWANTo and JEANINE PFEIFFER for their valuable comments on the manuscript.

\section{References}

Achere, V., P. Faivre Rampant, L. E. Paques and D. Prat (2004): Chloroplast and mitochondrial molecular tests identify European x Japanese larch hybrids. Theoretical Applied Genetics 108: 1643-1649.

Aitken, N., S. Smith, C. Schwarz and P. A. Morins (2004): Single nucleotide polymorphism (SNP) discovery in mammals: a targeted-gene approach. Molecular Ecology 13: $1423-1431$.

Batley, J., R. MogG, D. Edwards, H. O'Sullivan and K. J. EDWARDS (2003): A high-throughput SNuPE assay for genotyping SNPs in the flanking regions of Zea mays sequence tagged simple sequence repeats. Molecular Breeding 11: 111-120.

Bautista, R., R. Crespillo, F. M. Canovas and M. G. CLAROS (2002): Identification of olive-tree cultivars with SCAR markers. Euphytica 129: 33-41. 
BekKaoui, F., B. Mann and B. Schroeder (2003): Application of DNA markers for the identification and management of hybrid poplar accessions. Agroforestry Systems 59: $53-59$.

Brandstatter, A., T. J. Parsons and W. Parson (2003): Rapid screening of mtDNA coding region SNPs for the identification of west European Caucasian haplogroups. Int. J. Legal Med. 117: 291-298.

Brumfield, R. T., P. Beerli, D. A. Nickerson and S. V. EDWARDS (2003): The utility of single nucleotide polymorphisms in inferences of population history. Trends in Ecology and Evolution 18: 249-256.

Delaporte, K. L., G. G. Collins, J. G. Conran and M. SEDGLEY (2001): Molecular analysis of an interspecific hybrid ornamental eucalypt for parental identification. Euphytica 122: 165-170.

Don, R. H., P. T. Cox, B. J. WAINWRight, K. BAKER and J. S. MATTICK (1991): 'Touchdown' PCR to circumvent spurious priming during gene amplification. Nucleic Acids Research 19: 4008.

GERMANO, J and A. S. KLEIN (1999): Species-specific nuclear and chloroplast single nucleotide polymorphisms to distinguish Picea glauca, P. mariana and P. rubens. Theoretical Applied Genetics 99: 37-49.

Gros-Louis, M.-C., J. Bousquet, L. E. Paques and N. ISABEL (2005): Species-diagnostic markers in Larix spp. based on RAPDs and nuclear, cpDNA, and mtDNA gene sequences, and their phylogenetic implications. Tree Genetics \& Genomes 1: 50-63.

Gupta, P. K., J. K. Roy and M. Prasad (2001): Single nucleotide polymorphisms: A new paradigm for molecular marker technology and DNA polymorphism detection with emphasis on their use in plants. Current Science 80: 524-535.

Hattori, M., F. Tsukahara, Y. Furuhata, H. Tanahashi, M. Hirose, M. SAito, S. Tsukuni and Y. SAKAKI (1997): A novel method for making nested deletions and its application for sequencing of a $300 \mathrm{~kb}$ region of human APP locus. Nucleic Acids Research 25: 1802-1808.

Heaton, M. P., G. P. Harhay, G. L. Bennett, R. T. Stone, W. M. Grosse, E. Casas, J. W. Keele, T. P. L. Smith, C. G. ChitKo-McKown and W. W. LAEgREID (2002): Selection and use of SNP markers for animal identification and paternity analysis in U.S. beef cattle. Mammalian Genome 13: 272-281

Holderegger, R., S. Angelone, S. Brodbeck, D. CsenCSICS, F. Gugerli, S. E. Hoebee and R. Finkeldey (2005): Application of genetic markers to the discrimination of European Black Poplar (Populus nigra) from American Black Poplar (P. deltoids) and hybrid poplars (P. x Canadensis) in Switzerland. Trees 19: 742-747.

Huang, F., Y. P. B. C. Widyatmoko, B. X. Zhang and S. SHIRAISHI (2005): A diagnosis of Acacia hybrids between A. mangium and A. auriculiformis using codominant SCAR (sequence characterized amplified region) markers. Journal of Japanese Forest Society 87: 149-152. (in Japanese with English abstracts)

Jones, C. J., K. J. Edwards, S. Castaglione, M. O. Winfield, F. SAlA, C. VAN DE Wiel, G. BREDEMEIJER, B. Vosman, M. Matthes, A. Daly, R. Brettschneider, P. Bettini, M. Buiatti, E. Maestri, A. Malcevschi, N. Marmiroli, R. Aert, G. Volckaert, J. Rueda, R. LinACERo, A. VAzQUEZ and A. KARP (1997): Reproducibility testing of RAPD, AFLP and SSR markers in plants by a network of European laboratories. Molecular Breeding 3: 381-390.
Jones, E. S., H. Sullivan, D. Bhattramakki and J. S. C. SMITH (2007): A comparison of simple sequence repeat and single nucleotide polymorphism marker technologies for the genotypic analysis of maize (Zea mays L.). Theoretical Applied Genetics 115: 361-371.

Khasa, D., P. Pollefeys, A. Navarro-Quezada, P. Perinet and J. BousqUeT (2005): Species-specific microsatellite markers to monitor gene flow between exotic poplars and their natural relatives in eastern North America. Molecular Ecology Notes 5: 920-923.

Korol, L., A. Madmony, Y. Riov and G. Schiller (1995): Pinus halepensis x Pinus brustia subsp. brutia hybrids identification using morphological and biochemical traits. Silvae Genetica 44: 186-190.

LeE, H. Y., M. J. PARK, J-E. Yoo, U. Chung, G-R. HaN and K-J. SHIN (2005): Selection of twenty-four highly informative SNP markers for human identification and paternity analysis in Koreans. Forensic Science International 148: 107-112.

Lee, S.-H., D. R. Walker, P. B. Cregan and H. R. Boerma (2004): Comparison of four flow cytometric SNP detection assays and their use in plant improvement. Theoretical Applied Genetics 110: 167-174.

Mc Gregor, C. E., C. A. Lambert, M. M. Greyling, J. H. LOUW and L. WARNICH (2000): A comparative assessment of DNA fingerprinting techniques (RAPD, ISSR, AFLP and SSR) in tetraploid potato (Solanum tuberosum L.) germplasm. Euphytica 113: 135-144.

Mc Kinnon, G. E., R. E. Vaillancourt, P. A. Tilyard and B. M. PotTs (2001): Maternal inheritance of the chloroplast genome in Eucalyptus globulus and interspecific hybrids. Genome 44: 831-835.

Mohring, S., F. SAlamini and K. SchneIder (2004): Multiplexed, linkage group-specific SNP marker sets for rapid genetic mapping and fingerprinting of sugar beet (Beta vulgaris L.). Molecular Breeding 14: 475-488.

NG, C. H., S. C. KoH, S. L. LeE, K. K. S. NG, A. MarK, M. NORWATI and R. WICKNESWARI (2005): Isolation of 15 polymorphic microsatellite loci in Acacia hybrid (Acacia mangium x Acacia auriculiformis). Molecular Ecology Notes 5: 572-575.

NkongOLO, K. K. (1999): RAPD variations among pure and hybrid populations of Picea mariana, $P$. rubens, and P. glauca (Pinaceae), and cytogenetic stability of Picea hybrids: identification of species-specific RAPD markers. Plant Systematic and Evolution 215: 229-239.

PARAN, I. and R.W. Michelmore (1993): Development of reliable PCR-based markers linked to downy mildew resistance genes in lettuce. Theoretical Applied Genetics 85: 985-993.

Perron, M., A. G. Gordon and J. Bosquet (1995): Species-specific RAPD fingerprints for the closely related Picea mariana and P. rubens. Theoretical Applied Genetics 91: 142-149.

Pinso, C. and R. NAsi (1991): The potential use of Acacia mangium x Acacia auriculiformis hybrid in Sabah, pp. 17-21. In: Breeding technologies for tropical Acacias, edited by L. T. CARRON and K. M. AKEN. ACIAR Proceedings No. 37. Australia.

RAFALSKI, A (2002): Applications of single nucleotide polymorphisms in crop genetics. Current Opinion in Plant Biology 5: 94-100.

Scheepers, D., M. C. Eloy and M. BRIQUet (2000): Identification of larch species (Larix decidua, Larix kaempferi and Larix x eurolepis) and estimation of hybrid fraction in seed lots by RAPD fingerprints. Theoretical Applied Genetics 100: 71-74. 
Sedgley, M., J. Harbard, R. M. M. Smith, R. WickNESWARI and A. R. GRIFFIN (1992): Reproductive biology and interspecific hybridization of Acacia mangium and Acacia auriculiformis A. Cunn. ex Benth (Leguminosae: Mimosoideae). Australian Journal of Botany 40: 37-48.

ShIRAISHI, S and A. WATANABE (1995): Identification of chloroplast genome between Pinus densiflora Sieb. et Zucc and $P$. thunbergii Parl. based on polymorphisms in $r b c \mathrm{~L}$ gene. Journal of Japanese Forest Society 77: 429-436. (in Japanese with English abstracts)

TuRnBulL, J. W. (1986): Multipurpose Australia trees and shrubs: lesser known species for fuel wood and agroforestry. ACIAR Monograph No. 1, pp316.

Vallone, P. M., R. S. Just, M. D. Coble, J. M. Butler and T. J. PARSONS (2004): A multiplex allele-specific primer extension assay for forensically informative SNPs distributed throughout the mitochondrial genome. Int. J. Legal Med 118: 147-157.

VALlONE, P. M and J. M. ButleR (2004): Y-SNP typing of U.S. African American and Caucasian samples using allele-specific hybridization and primer extension. Journal of Forensic Sciences 49: 723-732.

Vallone, P. M, A. E. Decker, M. D. Coble and J. M. ButLER (2006): The evaluation of an autosomal SNP 12-plex assay. International Congress Series 1288: 61-63.
VARshney, R. K., U. Beier, E. K. KhlestKina, R. Kota, V. Korzun, A. Graner and A. Borner (2007): Single nucleotide polymorphisms in rye (Secale cereale L.): discovery, frequency, and applications for genome mapping and diversity studies. Theoretical Applied Genetics 114: 1105-1116.

Vignal, A., D. Milan, M. Sancristobal and A. EgGen (2002): A review on SNP and other types of molecular markers and their use in animal genetics. Genetics Selection Evolution 34: 275-305.

WenG, C., T. L. KubisiaK and M. STINe (1998): SCAR markers in a longleaf pine $\mathrm{x}$ slash pine $\mathrm{F} 1$ family. Forest Genetics 5: 239-247.

Werner, F. A. O., G. Durstewitz, F. A. Habermann, G. Thaller, W. Kramer, S. Kollers, J. Buitkamp, M. Georges, G. Brem, J. Mosner and R. Fries (2004): Detection and characterization of SNPs useful for identity control and parentage testing in major European dairy breeds. Animal Genetics 35: 44-49.

William, J. G., A. R. Kubelik, K. J. LivaK, J. A. RAFAlski and S. V. TINGEY (1990): DNA polymorphisms amplified by arbitrary primers are useful as genetic markers. Nucleic Acids Research 18: 6531-6535.

Yoon, M. S., Q. J. Song, I. Y. ChoI, J. E. SPECHT, D. L. Hyten and P. B. CREgAN (2007): BARCSoySNP23: a panel of 23 selected SNPs for soybean cultivar identification. Theoretical Applied Genetics 114: 885-899.

\title{
Short Note: Seven Genomic SSRs Revealed in Eucalyptus by Re-sequencing of DNA Sequences from GenBank
}

\author{
By X. $\mathrm{HE}^{1,2)}, \mathrm{F} . \mathrm{LI}^{1}$, J. $\mathrm{SHI}^{2)}$ and S. GAN $\left.{ }^{1, *}\right)$ \\ (Received 28 $8^{\text {th }}$ January 2010)
}

\begin{abstract}
Seven genomic SSR markers of Eucalyptus were developed from DNA sequences of $E$. grandis deposited in GenBank. Their repeat motifs were revealed by resequencing with an individual tree of $E$. urophylla or $E$. tereticornis, and five out of the seven markers turned out to be heterozygous within the specific tree sequenced. The sequence identity ranged from $75.06 \%$ to $96.66 \%$, with an average of $87.31 \%$. These markers

\footnotetext{
1) Research Institute of Tropical Forestry and National Key Laboratory of Forest Tree Genetics and Breeding, Chinese Academy of Forestry, Longdong, Guangzhou 510520, People's Republic of China.

$\left.{ }^{2}\right)$ The Key Laboratory of Forest Genetics and Biotechnology of Ministry of Education, Nanjing Forestry University, 159 Longpan Road, Nanjing 210037, People's Republic of China.

*) Corresponding author: Siming GAN. Tel: +86 2087032402 , Fax: +86 20 87031622. E-mail: Siming.Gan@ritf.ac.cn.
}

could be valuable in genetics studies in Eucalyptus. This report demonstrates the advantages of re-sequencing in developing SSR markers from publicly accessible databases.

Key words: Simple sequence repeats (SSRs), microsatellites, molecular markers, Eucalyptus, re-sequencing.

Simple sequence repeats (SSRs), as known as microsatellites, are useful markers for a wide spectrum of biological applications (POWELL et al., 1996; GUPTA and VARSHNEY, 2000). To date, a large number of SSR markers have been produced for a number of plant species, e.g. more than 5000 SSRs available for sorghum (Sorghum bicolor) (YonEMARU et al., 2009). In the woody genus Eucalyptus (family Myrtaceae), however, only 367 genomic SSRs (as reviewed in BRONDANI et al., 2006) and 68 EST-SSRs (FARIA et al., 2010, 2011; ZHOU et al., 